American J. of Engineering and Applied Sciences 5 (1): 9-14, 2012

ISSN 1941-7020

(C) 2014 N.A. Ebrahim et al., This open access article is distributed under a Creative Commons Attribution

(CC-BY) 3.0 license

\title{
Technology Use in the Virtual R\&D Teams
}

\author{
${ }^{1}$ Nader Ale Ebrahim, ${ }^{2}$ Shamsuddin Ahmed, \\ ${ }^{1}$ Salwa Hanim Abdul Rashid and ${ }^{2}$ Zahari Taha \\ ${ }^{1}$ Department of Engineering Design and Manufacture, \\ Faculty of Engineering, University of Malaya Kuala Lumpur, Malaysia \\ ${ }^{2}$ Faculty of Manufacturing Engineering and Management Technology, \\ University Malaysia Pahang, 26300 Gambang, Pahang, Malaysia
}

\begin{abstract}
Problem statement: Although, literature proves the importance of the technology role in the effectiveness of virtual Research and Development (R\&D) teams for new product development. However, the factors that make technology construct in a virtual R\&D team are still ambiguous. The manager of virtual $R \& D$ teams for new product development does not know which type of technology should be used. Approach: To address the gap and answer the question, the study presents a set of factors that make a technology construct. The proposed construct modified by finding of the field survey $(\mathrm{N}=240)$. We empirically examine the relationship between construct and its factors by employing the Structural Equation Modeling (SEM). A measurement model built base on the 19 preliminary factors that extracted from literature review. The result shows 10 factors out of 19 factors maintaining to make technology construct. Results: These 10 technology factors can be grouped into two constructs namely Web base communication and Web base data sharing. The findings can help new product development managers of enterprises to concentrate in the main factors for leading an effective virtual R\&D team. In addition, it provides a guideline for software developers as well. Conclusion: The second and third generation technologies are now more suitable for developing new products through virtual R\&D teams.
\end{abstract}

Key words: Collaboration teams, questionnaires performance, cross-functional teams, product development, structural equation modeling, measurement model, literature review

\section{INTRODUCTION}

Virtual teams are defined as "small temporary groups of geographically, organizationally and/or time dispersed knowledge workers who coordinate their work, mainly with electronic information and communication technologies to carry out one or more organization tasks" (Ebrahim et al., 2009b). Virtual R\&D team is a form of a virtual team, which includes the features of virtual teams and concentrates on R\&D activities (Ebrahim et al., 2011). The members of a virtual R\&D team use different degrees of communication technology to complete the research without space, time and organizational boundaries (Nader et al., 2010a, Husain and Yong, 2009). "We are becoming more virtual all the time!" is heard in many global corporations today (Chudoba et al., 2005). On the other hand, New Product Development (NPD) is widely recognized as a key to corporate prosperity (Lam et al., 2007). The specialized skills and talents needed for developing new products often remain locally in pockets of excellence around the company or even around the Corresponding Author: Nader Ale Ebrahim, Department of Engineering Design and Manufacture, Faculty of Engineering, University of Malaya Kuala Lumpur, Malaysia world. Therefore, enterprises have no choice but to disperse their new product units to access such dispersed knowledge and skills (Kratzer et al., 2005). As a result, enterprises are finding that internal development of all technology needed for new products and processes are difficult or impossible. They must increasingly receive technology from external sources (Stock and Tatikonda, 2004).

Virtualization in NPD has recently started to make serious headway due to developments in technologyvirtuality in NPD which is now technically possible (Leenders et al., 2003). As product development becomes the more complex, supply chain, also have to collaborate more closely than in the past. These kinds of collaborations almost always involve individuals from different locations, so virtual team working supported by Information Technology (IT), offers notable potential benefits (Anderson et al., 2007). Although the use of the internet in NPD has received notable attention in the literature, little is written about collaborative tool and effective virtual teams for NPD (Ebrahim et al., 2009a). In 
addition, literature shows the factors that make technology construct in a virtual R\&D team are still ambiguous. I this study we try to fill the gap in the literature.

This study is structured as follows. First, base on prior research we extract the 19 factors of technology construct in the virtual R\&D teams. Next, Structural Equation Modeling (SEM) is used as the analytical tool for testing the estimating and testing the technology construct measurement models. Then adjust the preliminary technology construct the model by fitting the model according to the SEM fitness indices and made a final measurement model. The study infers with a discussion and future guidelines.

Literature review: Virtual teams use digital communications, video and audio links, electronic whiteboards, e-mail, instant messaging, websites, chat rooms, as substitutes for physical collocation of the team members (Baskerville and Nandhakumar, 2007, Pauleen and Yoong, 2001). Simple transmission of information from point A to point B is not enough; the virtual environment presents significant challenges to effective communication (Walvoord et al., 2008). Being equipped with even the most advanced technologies are not enough to make a virtual team effective, since the internal group dynamics and external support mechanisms must also be present for a team to succeed in the virtual world (Lurey and Raisinghani, 2001). Virtual teams are technology-mediated groups of people from different discipline that work on common tasks (Dekker et al., 2008) so the way the technology is implemented seems to make the virtual teams outcome more or less likely (Anderson et al., 2007). Virtual R\&D team instructor should choose the suitable technology based on the purpose of the team (Ebrahim et al., 2009c).
Factors that make technology construct in a virtual R\&D team are still ambiguous. We extracted 19importance factors related to the technology construct, base on a comprehensive review on technology view in the virtual R\&D team working. Table 1 summarized the factors and their supported references. E-mails and conference calls are generally known as first generation technologies while online discussion boards, power point presentations, video tools and online meeting tools are second-generation technologies. Third generation technology refers typically to web-enabled shared workspaces with the intranet or internet (LeeKelley and Sankey, 2008).

Research method: To build a measurement model of technology construct in virtual R\&D teams for new product development, we conducted a web-based survey mainly in Malaysian and Iranian manufacturing enterprises, in a random sample of small and medium enterprises. Web-based survey method is selected because; it is a cost-effective and quick result to get feedback from the belief of the respondent. A Likert scale from one to five was used. This set up gave respondents a series of attitude dimensions. For each factor, the respondent was asked whether, the factor is not important or extremely important by using a Likert scale rating. The questionnaire was emailed to the managing director, $\mathrm{R} \& \mathrm{D}$ manager, the new product development manager, project and design manager and suitable people who were most familiar with the R\&D activities in the firm. The rapid expansion of Internet users has given web-based surveys the potential to become a powerful tool in survey research (Sills and Song, 2002, Nader et al., 2010b).

Table 1: Summary of the factors related to the technology construct in the virtual teams

\begin{tabular}{|c|c|c|}
\hline Factor name & Factor descriptions & References \\
\hline Tech1 & Use internet and electronic mail & $\begin{array}{l}\text { (Redoli et al., 2008, Pauleen and Yoong, 2001, } \\
\text { Lee-Kelley and Sankey, 2008, Thissen } \text { et al., 2007) }\end{array}$ \\
\hline Tech2 & Online meeting on need basis & $\begin{array}{l}\text { (Chen } \text { et al., 2007; Lee-Kelley and Sankey, 2008; } \\
\text { Pena-Mora } \text { et al., 2000; Thissen } \text { et al., 2007) }\end{array}$ \\
\hline Tech3 & Web conferencing & $\begin{array}{l}\text { (Coleman and Levine, 2007; Thissen et al., 2007, } \\
\text { Zemliansky and Amant, 2008; Ebrahim } \text { et al., 2009c) }\end{array}$ \\
\hline Tech4 & Seminar on the Web & (Zemliansky and Amant, 2008) \\
\hline Tech5 & Shared work spaces & (Lee-Kelley and Sankey, 2008) \\
\hline Tech6 & Video conferencing & (Chen et al., 2007; Zemliansky and Amant, 2008) \\
\hline Tech7 & Audio conferencing & (Chen et al., 2007; Lee-Kelley and Sankey, 2008; Zemliansky \\
\hline Tech8 & Online presentations & (Lee-Kelley and Sankey, 2008) and Amant, 2008) \\
\hline Tech9 & Share documents (off-line) & (Coleman and Levine, 2007; Ebrahim et al., 2009c) \\
\hline Tech10 & $\begin{array}{l}\text { Share what's on your computer desktop with people in } \\
\text { other locations (Remote access and control) }\end{array}$ & (Thissen et al., 2007; Ale et al., 2009) \\
\hline Tech11 & $\begin{array}{l}\text { Do not install engineering software } \\
\text { (get service through web browser) }\end{array}$ & $\begin{array}{l}\text { (Coleman and Levine, 2007; Kotelnikov, 2007, } \\
\text { Vasileva, 2009) }\end{array}$ \\
\hline Tech12 & Access service from any computer (in Network) & (Thissen et al., 2007; Vasileva, 2009) \\
\hline Tech13 & Standard phone service and hybrid services & (Thissen et al., 2007; Ebrahim et al., 2009c) \\
\hline Tech14 & Access shared files anytime, from any computer & (Lee-Kelley and Sankey, 2008) \\
\hline Tech15 & Web database & $\begin{array}{l}\text { (Coleman and Levine, 2007; Zemliansky and Amant, 2008; } \\
\text { Ebrahim } \text { et al., 2009c) }\end{array}$ \\
\hline Tech16 & Provide instant collaboration & (Coleman and Levine, 2007; Thissen et al., 2007) \\
\hline Tech17 & $\begin{array}{l}\text { Software as a service (canceling the need to install and run } \\
\text { the application on the own computer) }\end{array}$ & (Coleman and Levine, 2007; Thissen et al., 2007) \\
\hline Tech18 & Virtual research center for product development & (Zemliansky and Amant, 2008) \\
\hline Tech19 & Can be integrated/compatible with the other tools and systems & (Coleman and Levine, 2007; Kotelnikov, 2007) \\
\hline
\end{tabular}


Invitation e-mails were sent to each respondent, reaching 972 valid email accounts, with reminders following every two weeks up to three months. 240 enterprises completed the questionnaire, for an overall response rate of $24.7 \%$ Table 2 .

\section{RESULTS}

Anderson and Gerbing (1988) suggested using Confirmatory Factor Analysis (CFA) for scale development because it affords stricter interpretation of unidimensionality than what is provided by more traditional approaches, such as coefficient alpha, itemtotal correlations and exploratory factor analysis. The evidence that the measures were one-dimensional, where a set of indicators (factors) shares only a single underlying construct, was assessed using CFA (Anderson and Gerbing, 1988). After data collection, the measures purification procedures should be used to assess their reliability, unidimensionality, discriminate validity and convergent validity (Anderson and Gerbing, 1988).

For reliability analysis, Cronbach's Alpha (Cronbach, 1951) was employed to each factor. As shown in Table 3, all the items with Cronbach's $\alpha$ greater than threshold 0.6 were included in the analysis and the rest omitted from analysis. So, the factors Tech1, Tech10, Tech11 and Tech13 freed from further analysis. In general, the reliability of the questionnaire's instruments displayed a good reliability across samples.

Structural Equation Modeling (SEM) using AMOS 18 was employed for validation of the measurement model. This statistical analysis are estimated simultaneously for both the measurement and structural models (Dibrell et al., 2008). To ensure the factors make a right construct, the measurement model examined for model fit. Given this, the model assessed for the convergent and discriminant validity.

Table 2: Summarized online survey data collection

\begin{tabular}{lr}
\hline Numbers of emails sent enterprises & 3625 \\
\hline Total responses (Click the online web page) & 972.0 \\
Total responses / received questionnaire (\%) & 26.8 \\
Total completed & 240.0 \\
Total completed / received questionnaire (\%) & 24.7 \\
\hline
\end{tabular}

Convergent validity was established using a calculation of the factor loading, Average Variance Extracted (AVE) and Composite Reliability (CR). The factors that have standardized loadings exceeded 0.50 , were maintained (Dibrell et al., 2008). The initial measurement model was consisting of 19 factors (Tech1 to Tech19). After revising the measurement model by deleting Tech1, Tech10, Tech11 and Tech13, the AVE and CR were calculated. AVE larger than 0.5 is the threshold (McNamara et al., 2008). CR is calculated by squaring the sum of loadings, then dividing it by the sum of squared loadings, plus the sum of the measurement error (Lin et al., 2008). CR should be greater than 0.6 (Huang, 2009). The measurement model had acceptable convergent validity since the calculated CR and AVE were 0.930 and 0.613 respectively.

For discriminant validity, we performed AMOS software using Maximum Likelihood method (ML). The fitting indices checked with their respective acceptance values Table 4 . We run the AMOS for the model Ver1 (technology construct with 15 factors) and found a nonsignificant chi-square per degrees of freedom $(\mathrm{CMIN} / \mathrm{DF}=7.232)$. Most of the rest of fit indices was not in the acceptable range.

Table 3: Summary of the final measures and reliabilities

\begin{tabular}{lll} 
Factor name & $\begin{array}{l}\text { Corrected item- } \\
\text { total correlation }\end{array}$ & $\begin{array}{l}\text { Cronbach's alpha } \\
\text { if Item deleted }\end{array}$ \\
\hline Tech1 & 0.525 & 0.943 \\
Tech2 & 0.755 & 0.939 \\
Tech3 & 0.777 & 0.939 \\
Tech4 & 0.717 & 0.940 \\
Tech5 & 0.759 & 0.939 \\
Tech6 & 0.722 & 0.940 \\
Tech7 & 0.731 & 0.939 \\
Tech8 & 0.780 & 0.939 \\
Tech9 & 0.610 & 0.942 \\
Tech10 & 0.576 & 0.942 \\
Tech11 & 0.571 & 0.943 \\
Tech12 & 0.686 & 0.940 \\
Tech13 & 0.519 & 0.943 \\
Tech14 & 0.624 & 0.941 \\
Tech15 & 0.696 & 0.940 \\
Tech16 & 0.642 & 0.941 \\
Tech17 & 0.678 & 0.940 \\
Tech18 & 0.649 & 0.941 \\
Tech19 & 0.615 & 0.942
\end{tabular}

Table 4: Fitting indices (adopted from (Byrne, 2001)

Fit Indices Desired range

$\chi^{2} /$ degrees of freedom $(\mathrm{CMIN} / \mathrm{DF}) \leq 2.00$

IFI (Incremental Fit Index) $\geq 0.90$

Comparative Fit Index (CFI) Coefficient values range from zero to 1.00, with values close to 0.95 showing superior fit

RMSEA (Root Mean Squire values less than .05 show good fit and values as high as .08 represent reasonable fit,

Error of Approximation) from 0.08-0.10 show mediocre fit and those greater than 0.10 show poor fit

Root mean square residual (RMR) $\leq 0.08$

Goodness-of-Fit Index (GFI) $\quad \geq 0.90$

Normed Fit Index (NFI) Coefficient values range from zero to 1.00, with values close to 0.95 showing superior fit

Relative Fit Index (RFI) Coefficient values range from zero to 1.00, with values close to 0.95 showing superior fit

Tucker-Lewis Index (TLI) 


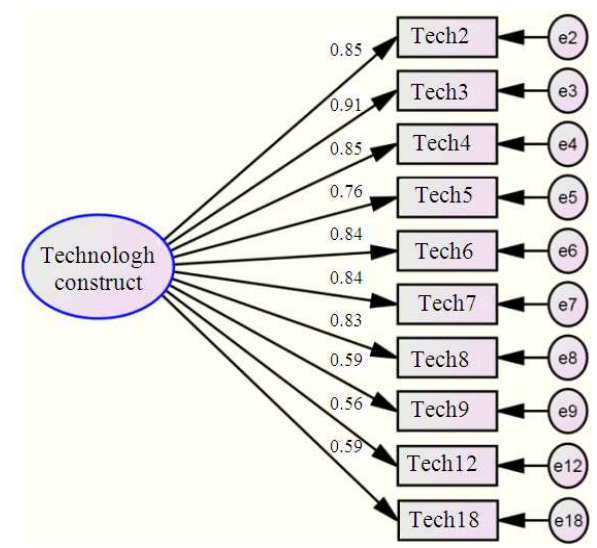

Fig. 1: Measurement model Ver2

Thus, refer to the AMOS Modification Indices (MI) some of the factors that had the lowest factor loading or the same effect of remaining factor, were deleted. With this modification, the measurement model Ver2 had a significant chi-square per degrees of freedom $(\mathrm{CMIN} / \mathrm{DF}=4.767)$; other fit indices, RMSEA, RMR and GFI also were in the acceptable range. Therefore, the best fitting model was the measurement model Ver2 Fig. 1 and it used for further analysis.

\section{DISCUSSION}

The final measurement developed made base on the measurement model ver2 by classifying the factors in two groups according to their relevant factor loading with the threshold 0.83 . The proper name for each group can be web base; communications and data sharing respectively. As displayed in Fig. 2 each factor loading was above 0.62 and significant. Overall, the final measurement model produced good fit indices $(\mathrm{CMIN} / \mathrm{DF}=2.889, \mathrm{RMR}=.04, \mathrm{GFI}=0.929, \mathrm{RFI}=$ $0.929, \mathrm{NFI}=0.949, \mathrm{TLI}=0.952, \mathrm{CFI}=0.966 \mathrm{IFI}=$ 0.964, RMSEA $=0.089$ ).

While fitting the technology construct the measurement model the factors Tech14 (access shared files anytime, from any computer), Tech15 (web database), Tech16 (provide instant collaboration), Tech17 (software as a service (eliminating the need to install and run the application on the own computer)) and Tech19 (can be integrated/compatible with the other tools and systems) were dropped. Modification indices (MI) base on regression weights shows Tech17, Tech 18 and Tech19 are highly correlated, so one representative (Tech18) from this group is enough. Tech14 to Tech16 are strongly correlated with Tech12, so the remaining factor represents the deleted ones.

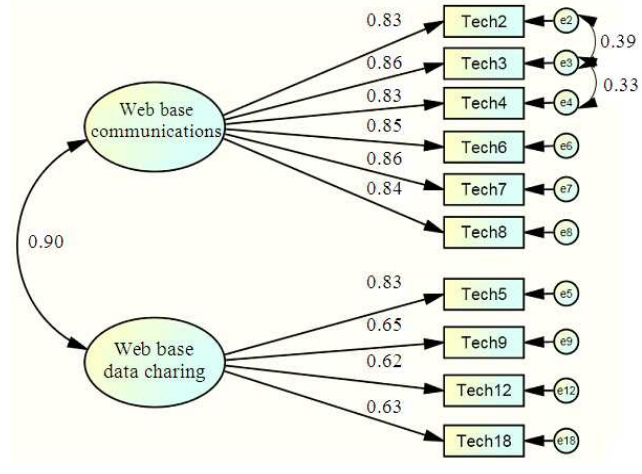

Fig. 2: Final measurement model

The results of the final measurement model of technology construct in virtual $R \& D$ team for developing a new product, shows the share of two main contrasts, which are strongly correlated to each other:

- Web base communications consists of online meeting on needed basis, web conferencing, seminar on the web, video conferencing, audio conferencing and online presentations

- Web base data sharing consists of shared work spaces, share documents (off-line), access service from any computer (in network) and virtual research center for product development

According to Lee-Kelley and Sankey (2008) these two constructs belong to the second and third generation of technology. Equip virtual R\&D team members with the suitable technology make the teams more effective. Therefore, the manager of NPD should provide the facilities and infrastructures for the virtual R\&D teams to achieve the higher level of team effectiveness.

\section{CONCLUSION}

Research so far has explored the 19 factors for working together virtually; however, us still less know about the factors which has main contributions in the technology construct of the virtual R\&D teams for New product development. The findings of this study extend the literatures and help to build a foundation for further understanding of the technology elements in the virtual R\&D teams for new product development. The measurement model shows ten factors that make the technology constructs. These ten factors can be sorted by their factor loading which are reflecting the factor weight. Therefore, the software developer or the managers of the NPD are able to provide a better 
platform for virtual team working by concentrating on the main factors. The second and third generation of technology (refer to definition of Lee-Kelley and Sankey (2008) is now more suitable for developing a new product through virtual R\&D teams.

Future research is needed to examine the effects of each factor to perform the virtual $R \& D$ teams while the others constructs of virtual teams such as process and people are present. A new SEM is needed to demonstrative the relationship between factorsconstructs and constructs-constructs which is not investigated yet in the literature.

\section{REFERENCES}

Ale, E., N. Ahme and Z. Taha, 2009. Innovation and Technology Facilitator University of Tehran.

Anderson, A.H., R. Mcewan, J. Bal and J. Carletta, 2007. Virtual team meetings: An analysis of communication and context. Comput. Human Behav., 23: 2558-2580. DOI: 10.1016/j.chb.2007.01.001

Anderson, J.C. and D.W. Gerbing, 1988. Structural equation modeling in practice: $\mathrm{A}$ review and recommended two-step approach. Psycholo. Bull., 103: 411-423. DOI: 10.1037/0033-2909.103.3.411

Baskerville, R. and J. Nandhakumar, 2007. Activating and perpetuating virtual teams: Now that we're mobile, where do we go? IEEE Trans. Profess. Commun., 50: 17-34. DOI: 10.1109/TPC.2006.890849

Byrne, B.M., 2001. Structural equation modeling with AMOS: Basic Concepts, Applications and Programming. 1st Edn., Routledge, USA., ISBN10: 0805841040 pp: 352.

Chen, M., Y. Liou, C.W. Wang, Y.W. Fan and Y.P.J. Chi, 2007. TeamSpirit: Design, implementation and evaluation of a Web-based group decision support system. Decision Support Syst., 43: 1186-1202. DOI: $10.1016 /$ j.dss.2005.07.008

Chudoba, K.M., E. Wynn, M. Lu and B.M. WatsonManheim, 2005. How virtual are we? Measuring virtuality and understanding its impact in a global organization. Inform. Syst. J., 15: 279-306. DOI: 10.1111/j.1365-2575.2005.00200.x

Coleman, D. and S. Levine, 2007. Collaboration 2.0: Technology and best practices for successful collaboration in a web 2.0 world. 1st Edn., Happy About, California, USA, ISBN-10: 1600050719 pp: 320 .

Cronbach, L.J., 1951. Coefficient alpha and the internal structure of tests. Psychometrika, 16: 297-334. DOI: $10.1007 / \mathrm{BF} 02310555$
Dekker, D.M., C.G. Rutte and V.D.P.T. Berg, 2008. Cultural differences in the perception of critical interaction behaviors in global virtual teams. Int. J. Intercu. Relations, 32: 441-452. DOI: 10.1016/j.ijintrel.2008.06.003

Dibrell, C., P.S. Davis and J. Craig, 2008. Fueling Innovation through Information Technology in SMEs. J. Small Bus. Manage., 46: 203-218. DOI: 10.1111/j.1540-627X.2008.00240.x

Ebrahim, N.A., S. Ahmed, Z. Taha, 2009a. Modified stage-gate: A conceptual model of virtual product development process. Afr. J. Marke. Manag, 1: 211-219.

Ebrahim, N.A., S. Ahmed, Z. Taha, 2009b. Virtual R\&D teams in small and medium enterprises: A literature review. Sci. Res. Essay, 4: 1575-1590. DOI: $10.2139 /$ ssrn. 1530904

Ebrahim, N.A., S. Ahmed, Z. Taha, 2009c. Virtual teams: A literature review. Australian J. Basic Applied Sci., 3: 2653-2669.

Ebrahim, N.A., S.H.A. Rashid, S. Ahmed, Z. Taha, 2011. The Effectiveness of Virtual R\&D Teams in SMEs: Experiences of Malaysian SMEs. Indu. Eng. Manag. Syst., 10: 109-114.

Huang, C.C., 2009. Knowledge sharing and group cohesiveness on performance: An empirical study of technology R\&D teams in Taiwan. Technovation, 29: 786-797. DOI: 1016/j.technovation.2009.04.003

Husain, A.J.A. and C.H. Yong, 2009. Utility-based policy management system for virtual organization. J. Comput. Sci., 5: 635-645. DOI: 10.3844/jcssp.2009.635.645

Kotelnikov, V., 2007. Kim Hak-Su Asia-Pacific Development Information Programme e-Primers for the Information Economy, Society and Polity. 1st Edn., ISBN: 9789748283937, pp: 27.

Kratzer, J., R.T.A.J. Leenders and J.M.L.V. Engelen, 2005. Keeping virtual R\&D teams creative. CBS Interactive.

Lam, P.K., K.S. Chin, J.B. Yang and W. Liang, 2007. Self-assessment of conflict management in clientsupplier collaborative new product development. Indus. Manag. Data Syst., 107: 688-714. DOI: 10.1108/02635570710750435

Lee-Kelley, L. and T. Sankey, 2008. Global virtual teams for value creation and project success: A case study. Int. J. Project Manag. 26: 51-62. DOI: 10.1016/j.ijproman.2007.08.010

Leenders, R.T.A.J., J.M.L.V. Engelen and J. Kratzer, 2003. Virtuality, communication and new product team creativity: A social network perspective. J. Eng. Technol. Manag., 20: 69-92. DOI: 10.1016/S0923-4748(03)00005-5 
Lin, C., C. Standing and Y.C. Liu, 2008. A model to develop effective virtual teams. Decision Support Syst., 45: 1031-1045. DOI: 10.1016/j.dss.2008.04.002

Lurey, J.S. and M.S. Raisinghani, 2001. An empirical study of best practices in virtual teams. Inform. Manage., 38: 523-544. DOI: 10.1016/S03787206(01)00074-X

Mcnamara, K., A.R. Dennis and T.A. Carte, 2008. It's the thought that counts: The mediating effects of information processing in virtual team decision making. Inform. Syst. Manage., 25: 20-32. DOI: 10.1080/10580530701777123

Nader, A.E., A. Shamsuddin and T. Zahari, 2010b. Virtual R\&D teams and SMEs growth: A comparative study between Iranian and Malaysian SMEs. Afr. J. Bus. Manage., 4: 2368-2379.

Nader, A.E., A. Shamsuddin, A. Rashid, S. Hanim and T., Zahari, 2010a. The Effectiveness of Virtual R\&D Teams in SMEs: Experiences of Malaysian SMEs. Proceedings of the 11th Asia Pacific Industrial Engineering and Management Systems Conference Dec. 9-9, Melaka, Malaysia. Kuala Lumpur, Malaysia: University of Malaya Press, pp: 1-6.

Pauleen, D.J. and P. Yoong, 2001. Facilitating virtual team relationships via Internet and conventional communication channels. Int. Res., 11: 190-202. DOI: 10.1108/10662240110396450

Pena-Mora, F., K. Hussein, S. Vadhavkar and K. Benjamin, 2000. CAIRO: A concurrent engineering meeting environment for virtual design teams. Artif. Intell. Eng., 14: 203-219. DOI: 10.1016/S0954-1810(00)00016-9

Redoli, J., R. Mompo, J. Garcia-Diez and M. LopezCoronado, 2008. A model for the assessment and development of Internet-based information and communication services in small and medium enterprises. Technovation, 28: 424-435. DOI: 10.1016/j.technovation.2008.02.008
Sills, S.J. and C. Song, 2002. Innovations in survey research an application of web-based surveys. Soc. Sci. Comp. Rev., 20: 22-30. DOI: 10.1177/089443930202000103

Stock, G.N. and M.V. Tatikonda, 2004. External technology integration in product and process development. Int. J. Oper. Production Manage., 24: 642-665. DOI: 10.1108/01443570410541975

Thissen, M.R., J.M. Page, M.C. Bharathi and T.L. Austin, 2007. Communication tools for distributed software development teams. Proceedings of the 2007 ACM SIGMIS CPR Conference on Computer Personnel Research: The Global Information Technology Workforce. New York, DOI: 10.1145/1235000.1235007

Vasileva, S.E., 2009. Authority-based and bottom-up diffusion of collaboration information technologies: Constraints and enablements. mba (mgmt information systems). Universitat Koblenz-Landau.

Walvoord, A.A.G., E.R. Redden, L.R. Elliott and M.D. Coovert, 2008. Empowering followers in virtual teams: Guiding principles from theory and practice. Comput. Human Behav., 24: 1884-1906. DOI: 10.1016/j.chb.2008.02.006

Zemliansky, P. and K.S. Amant, 2008. Handbook of Research on Virtual Workplaces and the New Nature of Business Practices. 1st Edn., IGI Global Snippet, Hershey PA, ISBN-10: 159904871X, pp: 733. 